\title{
PENGARUH TERAPI MUSIK INSTRUMENTALIA TERHADAP PENURUNAN INTENSITAS NYERI PERSALINAN KALA I AKTIF DI 3 BIDAN PRAKTEK MANDIRI NGEMPLAK BOYOLALI
}

\author{
KH. Endah Widhi Astuti, RD Rahayu, Noris Hadi Sri Mulyani \\ Kementerian Kesehatan Politeknik Kesehatan Surakarta Jurusan Kebidanan
}

\begin{abstract}
Absctract: Music Therapy, Pain Intensity, Active Phase Of The First Stage Of Labor. Pain during labor is a physiological condition. In the physiology of labor, pain began to arise in the latent phase of the first stage of labor and the active phase. The intensity of pain during labor affects the psychological condition of the mother, labor, and fetal well-being. To know the effect of instrumental music therapy on decreasing the intensity of pain labor during the active phase on the first stage of labor in 3 indepndent midwives practice in ngemplak Boyolali district. Type of pre-experimental research with one group pretest-posttest design. Population of this study is mother actice phase in the first stage of labor in three independents midwives in Ngemplak Boyolali between October 2013 to December 2013. The sampling used purposive sampling technique with a sample of 32 respondents. The measurement technique used a pain scale. The Data was processed by editing, coding, scoring and tabulating. The Data was analysed used a paired sample t-test. The majority of respondents aged between 20-35 years (93.8\%) with 2 children (43.8\%), the level of high school education (56.3\%), the overall family support (100\%) and less anxious (65.6\%). Numerical pain l evels before therapy is the majority of severe pain (68.8\%) and after music therapy decreased the numerical pain becomes moderate pain (78.1\%). The level of pain behavior before the majority of instrumental music therapy is severe pain and being with each 16 persons (50.0\%) and after intrumentalia music therapy decreased pain is pain with the majority being about 18 people (56.3\%). There is effect instrumental music therapy to decrease pain intensity numeric and the intensity of pain behavior in the labor Kala I active $(0.000<0.05)$. There is the effect of instrumental music therapy on decreasing the intensity of pain in the actve phase of the first stage of labor.
\end{abstract}

Keywords : Music Therapy, Pain Intensity, Active Phase Of The First Stage Of Labor

Abstrak: Nyeri persalinan merupakan suatu kondisi yang fisiologis. Secara fisiologi nyeri persalinan mulai timbul pada persalinan kala I fase laten dan fase aktif. Intensitas nyeri selama persalinan mempengaruhi kondisi psikologis ibu, proses persalinan, dan kesejahteraan janin. Untuk mengetahui pengaruh pemberian terapi musik instrumentalia terhadap penurunan intensitas nyeri persalinan kala I aktif. Jenis penelitian pre experimental dengan one group pretest-post test design. Populasi penelitian adalah ibu bersalin kala I aktif pada 3 BPM di wilayah Ngemplak Boyolali antara bulan Oktober 2013 sampai dengan Desember 2013. Teknik pengambilan sampel menggunakan purposive dengan sampel 32 responden. Teknik pengukuran menggunakan skala nyeri. Pengolahan data : editing, koding, skoring dan tabulating. Analisis data menggunakan paired sample t-test. Mayoritas responden berusia antara $20-35$ tahun $(93,8 \%)$ dengan 
2 anak (43,8\%), tingkat pendidikan SMA (56,3\%), keseluruhan mendapatkan dukungan keluarga $(100 \%)$ dan tidak cemas $(65,6 \%)$. Tingkat nyeri numerik sebelum terapi mayoritas adalah nyeri berat $(68,8 \%)$ dan setelah terapi musik mengalami penurunan nyeri numerik menjadi nyeri sedang $(78,1 \%)$. Tingkat nyeri perilaku sebelum terapi musik instrumentalia mayoritas adalah nyeri berat dan sedang dengan masingmasing sebanyak 16 orang $(50,0 \%)$ dan setelah terapi musik intrumentalia mengalami penurunan nyeri dengan mayoritas adalah nyeri sedang sebanyak 18 orang $(56,3 \%)$ Ada pengaruh terapi musik instrumentalia terhadap penurunan intensitas nyeri numerik dan penurunan intensitas perilaku nyeri pada persalinan Kala I Aktif $(0,000<0,05)$. Ada pengaruh pemberian terapi musik instrumentalia terhadap penurunan intensitas nyeri persalinan kala I aktif.

Kata Kunci : Terapi Musik Instrumentalia, Nyeri Numerik, Nyeri Perilaku

\section{PENDAHULUAN}

Nyeri persalinan merupakan suatu kondisi yang fisiologis. Secara fisiologi nyeri persalinan mulai timbul pada persalinan kala I fase laten dan fase aktif, pada fase laten. Nyeri disebabkan oleh kontraksi uterus dan dilatasi servik. Makin lama nyeri yang dirasakan akan bertambah kuat, puncak nyeri terjadi pada fase aktif. Intensitas nyeri selama persalinan mempengaruhi kondisi psikologis ibu, proses persalinan, dan kesejahteraan janin (Potter dan Perry, 2006).

Cara mengatasi rasa nyeri dapat dilakukan dengan metode farmakologi dan non farmakologi. Salah satu metode non farmakologi yang dapat dilakukan adalah teknik distraksi (Suzannec,2001 dalam Andarmoyo, 2013). Teknik distraksi adalah salah satu cara untuk mengurangi nyeri dengan mengalihkan perhatian kepada sesuatu yang lain sehingga kesadaran ibu terhadap nyerinya berkurang. Salah satu distraksi yang efektif adalah music karena terbukti menunjukkan efek yaitu mengurangi kecemasan dan depresi, menghilangkan nyeri, menurunkan tekanan darah dan menurunkan frekuensi denyut jantung
(Potter, 2002). Musik yang dipilih pada umumnya music lembut dan teratur, seperti Instrumentalia atau musik klasik Mozart (Erfandi,2009 dalam Husna, 2010)

\section{METODE PENELITIAN Jenis dan Desain Penelitian}

Penelitian ini adalah pre experimental dengan one group pretestpost test design.

Penelitian ini melakukan intervensi terhadap subyek penelitian berupa terapi musik instrumentalia. Dari responden yang dilakukan terapi musik intrumentalia dibandingkan intensitas nyeri sebelum dan sesudah dilakukan intervensi.

Skema desain penelitian ini sebagai berikut:

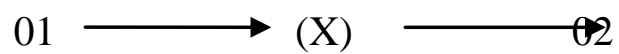

Keterangan :

$01=$ Pengukuran skala nyeri sebelum perlakuan.

$\mathrm{X}=$ Pemberian terapi musik

$02=$ Pengukuran skala nyeri setelah perlakuan. 


\section{Waktu dan Tempat Penelitian Tempat Penelitian}

Penelitian dilakukan di 3 Bidan Praktek Mandiri (BPM) di wilayah Kecamatan Ngemplak Kabupaten Boyolali yaitu BPM Noris Hadi, BPM Ririn Yuniati dan BPM Dyah Widya.

\section{Populasi dan Sampel}

Sampel yang digunakan dalam penelitian ini adalah semua ibu bersalin yang datang di 3 BPM di wilayah Ngemplak antara bulan Oktober sampai dengan Desember 2013 sejumlah $32 \mathrm{ibu}$ bersalin.dengan kriteria

a. Ibu bersalin kala I aktif

b. Bersedia menjadi responden

c. Keluarga mengijinkan untuk dilakukan terapi musik Instrumentalia

d. Dapat mendengar dengan baik.

\section{Tehnik Pengumpulan Data}

Peneliti dibantu tiga asisten peneliti dengan cara melakukan penilaian intensitas nyeri dengan menggunakan

1) skala nyeri numerik dan pedoman observasi perilaku nyeri persalinan kala I aktif dan Penilaian intensitas nyeri dilakukan sebelum dan setelah pemberian terapi musik instrumentalia, penilaian dilakukan saat responden dalam kala I aktif dan mencapai puncak kontraksi. Lembar Skala Nyeri Numerik (AHCPR, 1992 dalam Perry dan Potter, 2006) untuk menilai intensitas nyeri yang dirasakan responden dan diisi sendiri oleh responden 2) Lembar Skala Nyeri dengan Observasi Perilakua (Kozier, 2010), diisi oleh peneliti atau asisten.

\section{Analisa Data}

Analisa univariat dengan menggunakan tabel distribusi frekuensi untuk mengetahui karakteristik dari responden.. Uji normalitas data dilaksanakan dengan uji Kolomogorov Smirnov.

Analisa bivariat, jika data berdistribusi normal, analisis statistik yang digunakan untuk membandingkan nilai pre test dan post test dilakukan uji statistik parametrik dengan paried t-test. Jika data tidak berdistribusi normal digunakan uji nonparametrik dengan uji Wilcoxon

\section{HASIL PENELITIAN}

Hasil karakteristik responden diketahui bahwa mayoritas responden berusia antara 20 - 35 tahun $(93,8 \%)$. Mayoritas responden adalah multiparitas. Mayoritas responden mempunyai tingkat pendidikan menengah (56,3\%). Keseluruhan responden mendapatkan dukungan $(43,8 \%)$ keluarga terhadap terapi musik instrumentalia $(100 \%)$ dan mayoritas tidak cemas yaitu sebanyak 21 orang $(65,6 \%)$.

Status Emosi Responden

Responden yang cemas sebanyak 11 orang $(34,4 \%)$ dan responden yang tidak cemas sebanyak 21 orang $(65,6 \%)$. Berdasarkan hasil penelitian tersebut dapat diketahui bahwa mayoritas responden tidak cemas.

\section{Analisis}

Hasil penelitian menunjukkan bahwa intensitas nyeri numerik sebelum terapi musik instrumentalia diketahui responden dengan nyeri berat sebanyak 22 orang $(68,8 \%)$ dan nyeri sedang sebanyak 10 orang $(31,2 \%)$. Intensitas nyeri 
numerik setelah dilakukan terapi music intrumentalia diketahui responden dengan nyeri berat sebanyak 3 orang $(9,4 \%)$, nyeri sedang sebanyak 25 orang $(78,1 \%)$ dan nyeri ringan sebanyak 4 orang $(12,5 \%)$.

Berdasarkan hal tersebut maka mayoritas responden mengalami penurunan nyeri numerik setelah diberi terapi musik instrumentalia. Hasil penelitian menunjukkan bahwa intensitas nyeri perilaku sebelum dilakukan terapi musik instrumentalia diketahui responden dengan nyeri berat sebanyak 16 orang $(50,0 \%)$ dan nyeri sedang sebanyak 16 orang $(50,0 \%)$. Intensitas nyeri perilaku setelah dilakukan terapi musik intrumentalia diketahui responden dengan nyeri berat sebanyak 1 orang $(3,1 \%)$, nyeri sedang sebanyak 18 orang $(56,3 \%)$ dan nyeri ringan sebanyak 13 orang $(40,6 \%)$. Berdasarkan hal tersebut maka mayoritas responden mengalami penurunan nyeri perilaku setelah dilakukan terapi musik instrumentalia.

Analisis Bivariat Pengaruh Terapi Musik Instrumentalia Terhadap Penurunan Intensitas Nyeri Numerik

\begin{tabular}{llllll}
\hline Variabel & Perlakuan & Mean & $\begin{array}{l}\text { Norma } \\
\text { litas }\end{array}$ & T & $\begin{array}{l}95 \% \\
\text { CI }\end{array}$ \\
$\begin{array}{llllll}\text { Nyeri } \\
\text { Numerik }\end{array}$ & $\begin{array}{l}\text { Sebelum } \\
\text { Setelah }\end{array}$ & 7,13 & .127 & 13,392 & 0.000 \\
\hline
\end{tabular}

Hasil penelitian menunjukkan ratarata intensitas nyeri numerik sebelum dilakukan terapi musik instrumentalia $(7,13)$ sedangkan rata-rata intensitas nyeri numerik setelah dilakukan terapi musik instrumentalia $(4,88)$. Hasil uji normalitas dengan Kolmogorov- Smirnov diketahui bahwa nilai $p$ value pretest sebesar 0,127 $>0,0564$ sehingga data normal dan $p$ value postest $0,079>0,05$ sehingga data terdistribusi normal maka digunakan statistik parametrik yaitu uji paired sample $t$ test. Hasil uji statistik dengan paired sample t-test menunjukkan $p$ value $0,000<0,05$ sehingga ada pengaruh terapi music instrumentalia terhadap penurunan intensitas nyeri numerik pada persalinan Kala I Aktif di 3 Bidan Praktek Mandiri Ngemplak Boyolali. Hasil t-test pengaruh terapi musik instrumentalia terhadap penurunan intensitas perilaku nyeri.

\begin{tabular}{llllll}
\hline Variabel & Perlakuan & Mean & $\begin{array}{l}\text { Norm } \\
\text { litas }\end{array}$ & T & $\begin{array}{l}95 \% \\
\text { CI }\end{array}$ \\
Nyeri & Sebelum & 6,72 & .120 & 16,573 & 0.000 \\
Numerik & Setelah & 3,66 & .238 & & \\
\hline
\end{tabular}

Hasil penelitian menunjukkan ratarata intensitas perilaku nyeri sebelum dilakukan terapi musik instrumentalia $(6,72)$ sedangkan rata-rata intensitas perilaku nyeri setelah dilakukan terapi music instrumentalia (2,66). Hasil uji normalitas dengan Kolmogorov-Smirnov diketahui bahwa nilai $p$ value pretest sebesar 0,120>0,05 sehingga data normal dan $p$ value postest $0,238>0,05$ sehingga data terdistribusi normal maka digunakan statistik parametrik yaitu uji paired sample $t$ test. Hasil uji statistik dengan paired sample t-test menunjukkan $p$ value $0,000<0,05$ sehingga ada pengaruh terapi music 65 instrumentalia terhadap penurunan intensitas perilaku nyeri pada persalinan Kala I Aktif di 3 Bidan Praktek Mandiri Ngemplak Boyolali.

\section{PEMBAHASAN}

Hasil penelitian menunjukkan pengaruh terapi musik instrumentalia terhadap penurunan intensitas nyeri persalinan kala 1 Aktif baik untuk penurunan nyeri numerik maupun perilaku nyeri. Pengukuran intensitas nyeri dengan kedua skala tersebut tidak ada perbedaan, yaitu sama-sama menunjukkan penurunan 
intensitas nyeri. Hal ini dapat dilihat dari nilai $p$ value intensitas nyeri numerik dan perilaku nyeri adalah $(0,000<0,05)$.

Hasil penelitian ini sesuai dengan pernyataan dari Livingston, 1985 dalam Mander, (2004) bahwa musik bisa juga digunakan dalam upaya meminimalkan nyeri persalinan, bagaimana kerja musik membantu wanita menghadapi nyeri persalinannya terletak pada distraksinya dan kemampuannya untuk seseorang mengubah persepsi waktu .68 Nyeri persalinan merupakan suatu kondisi yang fisiologis. Secara fisiologi nyeri persalinan mulai timbul pada persalinan kala I fase laten dan fase aktif, pada fase laten terjadi pembukaan sampai $3 \mathrm{~cm}$, fase aktif terjadi pembukaan $4-10 \mathrm{~cm}$. Nyeri disebabkan oleh kontraksi uterus dan dilatasi servik, semakin lama nyeri yang dirasakan akan bertambah kuat, puncak nyeri terjadi pada fase aktif. Intensitas nyeri selama persalinan mempengaruhi kondisi psikologis ibu, proses persalinan, dan kesejahteraan janin (Potter dan Perry, 2006).

Musik dapat memberikan energi dan membawa perintah melalui irama sehingga musik dengan tempo yang tepat dapat membantu wanita mengatur pernapasannya selama nyeri persalinan (Di Fraco,1998 dalam Mander, 2004). Musik yang sering dipakai dalam distraksi nyeri adalah musik klasik. Beberapa penelitian telah membuktikan bahwa dengan mendengarkan musik terutama musik klasik dapat mengurangi kecemasan, tingkat ketegangan dan emosi atau nyeri fisik. Musik dapat digunakan untuk mengurangi stres penyebab rasa sakit dan mengendurkan otot - otot yang menegang sebagai reaksi terhadap rasa sakit tersebut. Musik juga mengubah persepsi waktu, yang menolong mengurangi rasa sakit yang diderita. (Kate dan Mucc, 2000, dalam Prasetya 2008) Hasil penelitian ini mendukung penelitian dari Husna (2010)

menunjukkan bahwa terapi musik Instrumentalia efektif untuk menurunkan intensitas nyeri persalinan kala I aktif.

\section{KESIMPULAN DAN SARAN}

Ada pengaruh terapi musik instrumentalia terhadap penurunan intensitas nyeri pada persalinan Kala I Aktif di 3 Bidan Praktek Mandiri Ngemplak Boyolali $(0,000<0,05)$. Hal ini dibuktikan dengan rata-rata intensitas nyeri numeric sebelum dilakukan terapi musik instrumentalia $(7,13)$ dan rata-rata intensitas nyeri numerik setelah dilakukan terapi music instrumentalia mengalami penurunan menjadi (4,88), sedangkan rata-rata intensitas perilaku nyeri sebelum dilakukan terapi musik instrumentalia $(6,72)$ dan rata-rata intensitas perilaku nyeri setelah dilakukan terapi musik instrumentalia mengalami penurunan menjadi $(2,66)$

\section{DAFTAR RUJUKAN}

Andarmoyo, S, Suharti. 2013, Persalinan Tanpa Nyeri Berlebihan, Jogjakarta: Ar - Ruzz Media

Cunningham, Gary F. 2009. Obstetri Williams. Jakarta : EGC.

Hidayat, A. 2007, Riset Keperawatan dan Teknik penulisan Ilmian, Jakarta: Salemba Medika.

Husna, U. 2010, Pengaruh Terapi Musik Instrumental Terhadap Perbedaan Intensitas Nyeri Persalinan Fase Aktif Kala 1 Pada Primigravida Di Wilayah Kerja Puskesmas Dangung Dari : http://Tepositoty.Unand.ac.id(30 agustus 2013) 
Judha, M., Sudarti \& Fauziah, A., 2012, Teori Pengukuran Nyeri dan Nyeri Persalinan, Yogyakarta: Muha Medika.

Kozier, B. 2010, Buku Ajar Fundamental Keperawatan : Konsep, Proses, dan Praktik Ed 7. Vol 1, New Jersey: Pearson Education Inc.

Mander, Rosemary. 2004, Nyeri Persalinan, Jakarta: EGC.

Notoatmojo, S. 2005, promosi Kesehatan dan Teori Aplikasi, Jakarta: Rineke Cipta.

Nursalam. 2008, Konsep dan Penerapan Metodelogi Penelitian Ilmu Keperawatan, Jakarta: Salemba Medika.

Pariani, S. 2010, Pendekatan Praktis Metodelogi Riset Keperawatan, Jakarta : CV Agung Seto.

Potter, P. A., \& perry, A.G. 2006, Buku Ajar Fundamental Keperawatan, Jakarta : EGC.

Prasetya, H. 2008, Perbedaan Terapi Musik Klasik dan Musik Rohani UntukMenurunkan Kecemasan Pasien di Bangsal Baugenvile Rumah Sakit Panti Waluyo, Surakarta: Poltekkes.

Prasetyo,S.N, 2010, Konsep dan Proses Perawatan Nyeri, Yogyakarta: Graha Ilmu.

Saryono, 2008, Metodologi Penelitian Kesehatan, Jogjakarta : Mitra Cendekia

Simkin, P \& Ancheta, R. 2005, Buku Saku Persalinan. Jakarta: Buku Kedokteran EGC.

Smeltzer, S.C BareB.G. 2002, Buku Ajar Keperawatan MedikalBedah.Jakarta:EGC.

Sugiono, 2008, Metode Penelitian Kuantitatif \& Kualitatif, Bandung : Alfabeta.
Sugiono. 2010, Statistika Untuk Penelitian, Bandung: Alfabeta.

Tamsuri, A. 2007, Konsep dan Penatalaksanaan Nyeri, Jakarta: Buku Kedokteran EGC.

Wiknjosastro, H. 2007, Ilmu Kebidanan, Jakarta : Yayasan Bina Pustaka Sarwono Prawiroharjo. 